\title{
Farmer's Knowledge Level about Recommended Brinjal Production Technology
}

\author{
Arvind Kumar Singh ${ }^{1 *}$, Amit Chatterjee ${ }^{1}$, Y. D. Mishra ${ }^{1}$ and Priyanka Jadon ${ }^{2}$ \\ ${ }^{1}$ Department of Agricultural Extension, Rajmata Vijayaraje Scindia Krishi Vishwa Vidyalaya, \\ Gwalior - 474002, Madhya Pradesh, India \\ ${ }^{2}$ Indian Institute of Soil Science, Bhopal-462038, Madhya Pradesh, India \\ *Corresponding author
}

\section{A B S T R A C T}

\begin{tabular}{|l|}
\hline Key w or d s \\
$\begin{array}{l}\text { Knowledge level } \\
\text { and Brinjal } \\
\text { Production } \\
\text { Technology }\end{array}$ \\
\hline Article Info \\
\hline $\begin{array}{l}\text { Accepted: } \\
\text { 05 June } 2020 \\
\text { Available Online: } \\
\text { 10 July } 2020\end{array}$ \\
\hline
\end{tabular}

The present study was conducted during 2016-17 to assess the knowledge level of farmers about Brinjal production technology. A total of 120 Brinjal growers were selected randomly from 10 villages of Gohad block of Bhind district (M.P.). For data collection, the respondents were interviewed with the help of a structure interview schedule containing questions on Brinjal production technology. Each component has been assigned a particular score to assess knowledge level of Brinjal growing farmers. The collected data were analyzed with suitable statistical methods. The study concludes that more than fifty percent $(62.50 \%)$ respondents had medium level of knowledge while only $19.17 \%$ falls in the category of high level of knowledge about recommended Brinjal production of technology. This may be due lack of exposure towards agricultural messages from interpersonal and mass media channels.

\section{Introduction}

The vegetables are an essential requirement of the daily human diet, because of its nutritional value. Regular uses of vegetables provide us most of the essential health building and protecting substances, such as vitamins and minerals. In India, vegetarianism has been a way of life since the early days of recorded history. The problem of under nutrition and malnutrition can be solved by ensuring balanced diet for all. Vegetables are grown in
India since thousands of years, but now-adays it has become an important enterprise of farmers for better earnings and livelihood security.

Brinjal or eggplant (Solanum melongea L.) belongs to Solanaceae family. It originated in India. According to USDA, production of eggplant is highly concentrated. China is the top producer having 55 per cent of production from world and India is second producer having about 28 per cent share with 8,200,000 
MT total productions (Anonymous, 2006). It is an important and indigenous vegetable crop of India. It contributes 9 per cent of the total vegetable production of the country. It occupies the third position amongst vegetable crops. West Bengal is the largest producer of Brinjal followed by Maharashtra and Bihar.

The other main states growing Brinjal are Karnataka, Gujarat, and Andhra Pradesh. Recent data of area and production of the Brinjal growing districts exemplify that areas under Brinjal cultivation have been increased however, the yield in downfall year by year. Therefore, there is a wide gap between the average yield of farmer's field and the potential yield of the crop. Certain problems have been observed in Brinjal cultivation.

In recent years, many agricultural technologies have been developed by research agencies for the utilization to farming communities. Various extension agencies are continuously making efforts to create awareness among the farmers about such technologies, so that the growers may adopt these technologies and enhance their production.

The production technology of vegetables has been changing with a faster pace as compare to other field crops because of their sensitivity towards various pests. Despite of enormous efforts by research and extension agencies in recent past, it has been observed from the yield data of past years that there is still wide gap between existing production level and the expected production level.

Looking to this scenario and importance of Brinjal crop in food habits of vegetarian population of study area, a study was undertaken to assess the Farmer's Knowledge Level about Recommended Brinjal Production Technology and its relationship with the profile of the Brinjal growers.

\section{Materials and Methods}

The study was conducted in purposively selected Bhind district of Madhya Pradesh during 2016-17. District Bhind consists of six blocks, out of six blocks, Gohad block of Bhind district was selected due to ceiling area under Brinjal cultivation.

A list of Brinjal growing villages in the block was prepared on the basis of secondary data. From the list, ten villages namely Birkhadi, Sarva, Tukeda, Chhimka, Sipari, Sirsoda, Lehteera, Barthara, Bagulari and Bhagbasar with a sizable number of Brinjal growers were selected for the study.

Out of selected villages, 12 farmers from each village were randomly chosen as respondents. Thus, a total of 120 farmers served as sample for the study. The data were collected from the respondents through personal interviews with the help of a structure interview schedule containing questions on Brinjal production technology.

Each component has been assigned a particular score to assess knowledge level of Brinjal growing farmers. The collected data were analyzed by using statistical methods like mean, percentage, standard deviation, Karl Pearson's Correlation coefficient (r) for proper interpretation and inferences.

The Knowledge level of recommended package of practices about Brinjal was measured with the help of assigning selfscore. The components of each selected practices were made comprehensive with the help of concerned scientists.

The responses were recorded on three-point continuum as complete, partial and no knowledge and were given 2, 1 and 0 scores, respectively. On the basis of Mean $\pm \mathrm{SD}$, the respondents were categorized into low, 
medium and high groups. The knowledge index was calculated with following;

Knowledge Index $=\frac{\begin{array}{c}\text { Sum of knowledge score actually } \\ \text { obtained by the respondents }\end{array}}{\text { Maximum possible knowledge score }} \times 100$

Further, the respondents were classified into three categories by using following formula:

K.I. $=$ Mean \pm S.D. (Standard Deviation)

\begin{tabular}{|l|l|}
\hline \multicolumn{1}{|c|}{ Categories } & Score \\
\hline Low level $(<45)$ & Mean - S.D. \\
\hline Medium level $(45$ to 64$)$ & Mean \pm S.D. \\
\hline High level $(>64)$ & Mean + S.D. \\
\hline
\end{tabular}

\section{Results and Discussion}

The data given in Table 1 shows knowledge level of respondents about Brinjal production technology. The data reveals that about two third of the respondents $(62.50 \%)$ had medium knowledge about collective Brinjal production technologies, followed by 19.17 per cent who have categorized under high level of knowledge. It is notable that only 18.33 per cent of the respondents fall under low knowledge level category.

Thus, it can be concluded that majority of the respondents had medium level of knowledge of Brinjal production technology which can be increased with effective extension interventions like training, demonstrations and exposure visits.
Relationship of socio-economic and personal attributes of brinjal growers with their knowledge level

Pearson's coefficient of correlation was worked out to determine the relationship between Brinjal growers' socio-economic and personal attributes like age, education, land holding, annual income, source of information, material possession, farm power $\&$ equipment and credit facility with level of knowledge about recommended Brinjal production technologies.

It is evident from the data shown in Table - 2 that education and source of information were positively and significantly correlated with knowledge level about recommended Brinjal production technologies at 1 per cent level of significance and 5 percent level of significance, respectively.

It is also clear from the table that age, land holding, annual income, source of information, material possession, farm power $\&$ equipment and credit facility were nonsignificantly correlated with knowledge regarding recommended Brinjal production technologies. Correlation analysis showed that the vegetable farmers with high level of education, annual income were having more knowledge about recommended Brinjal production technologies as comparison to those with lower in level on above attributes.

Table.1 Distribution of respondents according to their knowledge level

\begin{tabular}{|l|c|c|}
\hline \multicolumn{1}{|c|}{ Categories } & Number of respondent & Percentage \\
\hline Low $(<45.16)$ & 22 & 18.33 \\
\hline Medium $(45.16$ to 63.6$)$ & 75 & 62.50 \\
\hline High $(>63.6)$ & 23 & 19.17 \\
\hline
\end{tabular}


Table.2 Relationship between personal and socio-economic attributes of brinjal growers with their knowledge level

\begin{tabular}{|l|c|}
\hline \multicolumn{1}{|c|}{ Socio-economic attributes } & Correlation Coefficient (r) \\
\hline Age & $-0.103 \mathrm{NS}$ \\
\hline Education & $0.210^{*}$ \\
\hline Land holding & $-0.052 \mathrm{NS}$ \\
\hline Annual income & 0.1 .1 \\
\hline Source of information & $0.329 * *$ \\
\hline Material possession & 0.105 \\
\hline Farm power and equipment & 0.084 \\
\hline Credit facility & 0.116 \\
\hline
\end{tabular}

* Significant at $\mathrm{p}=0.05 * *$ Significant at $\mathrm{p}=0.01 \mathrm{NS}-$ Non Significant

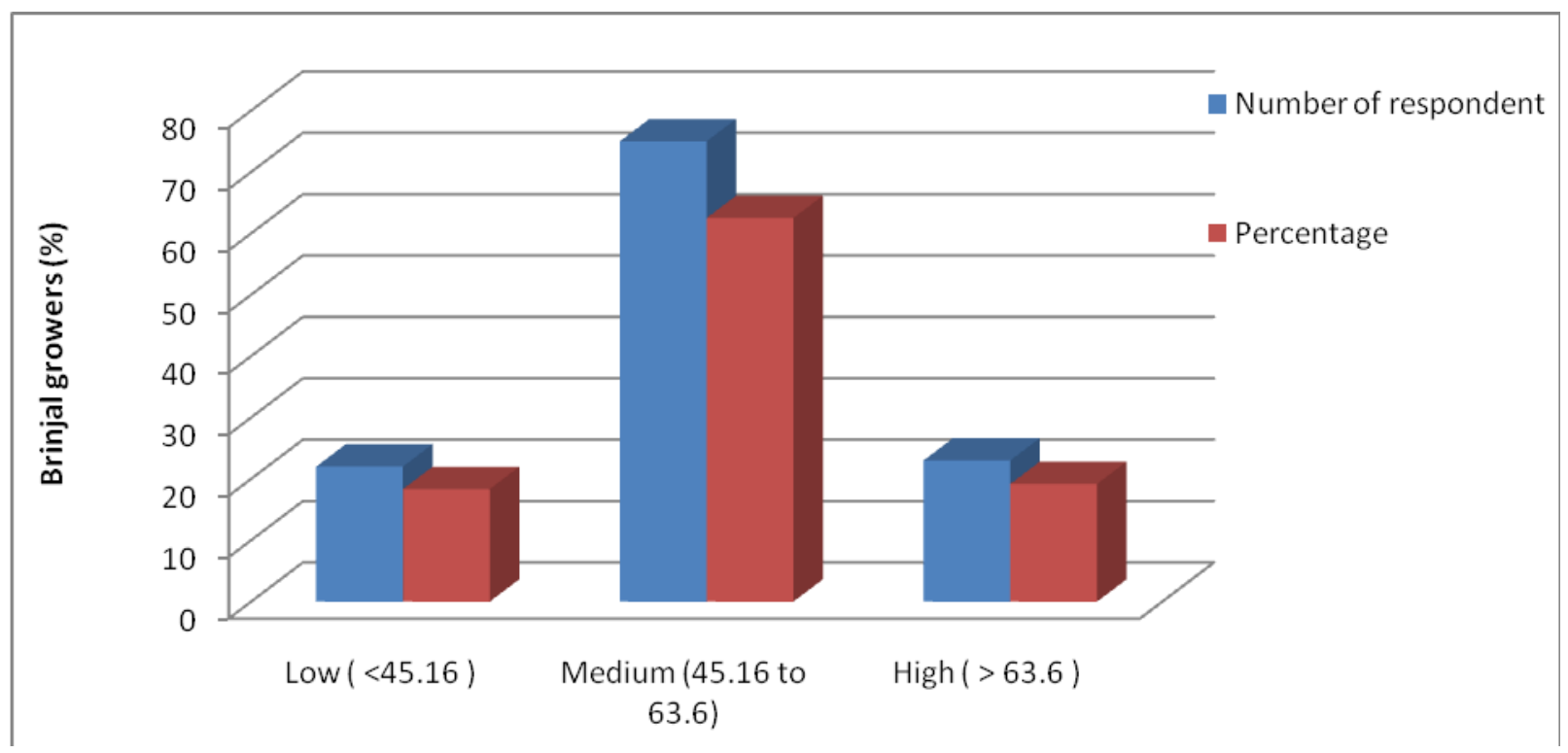

Fig.1 Distribution of respondents according to their knowledge level about improve brinjal cultivation practice

It can be concluded that majority of the respondents $(62.50 \%)$ had medium level of knowledge about Brinjal production technology. The knowledge level of Brinjal growers has been significantly contributing in efficient handling of crop during vulnerable situations. The existing knowledge gap can be filled with the micro level realistic planning and implementation of extension interventions like real time connectivity through ICTs, hands on training and potential exposure visits. It is a well-established fact that the education and information decisively contributes in end results in all spheres.

The present study also concludes that the education and source of information were positively and significantly correlated with knowledge level of recommended Brinjal production technology. 
However, other socio-personal attributes viz; age, land holding, annual income, source of information, material possession, farm power $\&$ equipment and credit facility were nonsignificantly correlated with knowledge level of farmers.

Hence, the focus of extension machinery should be in education and information level of the farmers for desired results.

\section{References}

Mewada Singh (2004). A study on training needs as perceived by the adopted farmers of KVK, Ichhawar of Sehore district (M.P.). M.Sc. (Ag.) Thesis (unpublished), JNKVV, Jabalpur.

Panicker, Beena and M. R. Chaudhari (2000). Training needs of farm women in modernizing agriculture. Maharashtra J. Extn. Edn. 19: 86-88.

\section{How to cite this article:}

Arvind Kumar Singh, Amit Chatterjee, Y. D. Mishra and Priyanka Jadon. 2020. Farmer's Knowledge Level about Recommended Brinjal Production Technology. Int.J.Curr.Microbiol.App.Sci. 9(07): 242-246. doi: https://doi.org/10.20546/ijcmas.2020.907.027 